\title{
1. Introduction: timeless signs or signs of the times?
}

\author{
Dev S. Gangjee
}

After existing at the margins for over a century, Geographical Indications (GI) scholarship has come of age. Recognising and celebrating its maturity, this edited collection has two objectives: (1) to gather together the most insightful and interesting research, as a convenient and enduring point of reference; and (2) to facilitate an interdisciplinary conversation, allowing future avenues of enquiry to emerge from the themes and insights which follow. In looking back across several decades of deliberations, disagreements and experiments, the contributions in this volume offer up productive ways of looking forwards.

In an increasingly globalised world, place and provenance matter as never before. Regimes regulating the use of GIs set out the conditions under which these signs signalling the provenance of products can be formally recognised and protected, the criteria to be satisfied when collectively using such signs and the extent to which these signs are protected against 'outsiders'. The law relating to GIs therefore protects products such as Rioja, Darjeeling and Café de Colombia. It is certainly true that GI protection is directed towards ensuring accurate information provision about geographical origin and quality in the marketplace, while simultaneously protecting commercially valuable reputations. Such designations are channels of communication and - like trade marks - incorporate this origin-signalling function. Yet it is also claimed that GIs are justifiably different and this assertion rests upon the unique or distinctive link between such regional products and their places of origin. The most influential articulation of this link is the French notion of terroir, originally associated with viticulture and periodically reinvented not only in France but subsequently across the EU, then in New World wine-producing countries and most recently across the global South.

The centrality of this link to place opens up an additional dimension of regulation in sui generis GI protection regimes. While they are designed to regulate the use of signs in the marketplace, they are additionally via the formal product specification or cahiers des charges - implicated in defining 'authentic' or historically stabilised products as well as collectively generated production techniques. Thus both signs and the 
products they represent are the objects of regulation. Moving further back along the chain of production, GIs are seen as potential bulwarks against commoditisation because they do not merely designate what the product is (its appearance or physical and organoleptic qualities) but also where, by whom and how - very specifically - it was made. This anchorage to place and inter-generational, collective investment has led to additional policy implications and justificatory accounts for GI regimes, ranging from enabling endogenous territorial development to biodiversity preservation and even cultural heritage recognition. These justifications extend well beyond the informational efficiency paradigm (ensuring uncluttered signalling in the marketplace), which otherwise accounts for the legal protection of signs against misrepresentation. In précis, these additional justificatory layers are put to work to explain the broader scope of protection as well as enforcement mechanisms for GIs. Consequently, when contrasted with trade marks sui generis GI regimes are seen as more prescriptive or demanding. Since the link to place is what sets GIs apart, the verification of this link and causally related product qualities calls for greater scrutiny and public oversight during the registration process, as well as subsequently during commercial use.

As a distinct regime within the categories of intellectual property law, GIs are therefore both conceptually and normatively intriguing. However, there remains the persistently practical as well as controversial question of how best to protect them. Debates occur both at the national level (for instance, involving the choice between sui generis or trade mark law regimes) as well as internationally (exploring the unfinished business left behind by the WTO's TRIPS Agreement). Unresolved issues remain in relation to the nature of the link between product and place; the design and implementation of sui generis GI protection; whether trade mark law is a viable alternative; the interaction between trade marks and GIs; and ongoing bilateral as well as multilateral negotiations to improve upon the scope - as well as limits - of international GI protection.

These questions have attracted not only specialists in intellectual property law but increasingly, researchers across disciplines in the social sciences and beyond. The greatest strength of this volume is that historians, geographers, sociologists, economists and anthropologists have joined legal scholars, legal practitioners and senior IP bureaucrats in unpacking this link between products and places, as well as the legal claims resting upon this link. This volume is therefore indispensable for both new entrants to this complex yet compelling field and established researchers, who should enjoy the interdisciplinary provocation from experienced contributors. A second virtue is that the contributors include both friends and critics (or in some cases, friendly critics) of GIs. 
You will find chapters following divergent paths in their interpretations of WTO panel rulings, the benefits of the Lisbon Agreement, the extent to which GIs can deliver on endogenous development goals or can be responsive to custodians of indigenous knowledge. There is productive disagreement within these pages. The third distinctive feature of this volume is that its coverage is intended to reflect each of the principal institutional layers as well as major debates in this area, in so far as word limits will permit. Readers will find the international treaties and institutional architecture established by WIPO, the WTO and certain bilateral initiatives analysed in detail by expert commentators. This is complemented by in-depth coverage of the origins and operation of the influential French appellation system, distinct new world regimes such as Australia's wine GI system and Asian experiments with GIs, including coverage of China and India. One of the most exciting recent developments - the redrafting of the Lisbon Agreement in 2015 - is analysed in Chapters 5, 6 and 14.

Consequently, one emergent question addressed in different ways is the extent to which a regime arising within a specific European historical and institutional context can be adapted and successfully transplanted elsewhere. A second is the extent to which we may be witnessing the beginnings of a truly global approach to GIs, arising from the acceleration of bilateral and plurilateral agreements and driven by the prospect of international registration. A third line of analysis explores the extent to which GIs could (in theory) and are (in practice) delivering on goals like heritage preservation or embedded development.

The value of an interdisciplinary approach to GIs is evident in Part I, which covers these historical, institutional and conceptual moorings. Chapter 1 opens with the meticulous archival analysis of Alessandro Stanziani, revealing that the French wine appellation system originated in attempts to stabilise and co-ordinate completely new vine-growing and wine-making practices in the post-phylloxera era. As opposed to merely recognising historical or 'authentic' products, these laws were directed towards reconciling innovation with tradition, allowing growers and producers to negotiate the content of acceptable wine production techniques, thereby achieving workable compromises. Disputes usually related to geographical boundaries of regions or the extent to which a practice qualified as traditional or 'loyal'. Accurately informing consumers about the provenance of wine was a secondary or incidental objective. As opposed to their external or consumer-facing signalling functions, Stanziani therefore emphasises the internal dynamics shaping the definitions of both regions and products. He suggests that these early legislative episodes prioritised regulating the fairness of producers' and wine growers' conduct inter se, 
as opposed to consumer protection. This internal aspect of GIs is further developed by the remaining two chapters in Part I.

In Chapter 2, Elizabeth Barham takes up the challenge of 'translating terroir', exploring the conceptual origins, normative goals and political economy potential of this controversial link to place. She draws on conventions theory - an institutionalist approach to studying economic co-ordination - to outline the ways in which GIs challenge neo-liberal conceptualisations of industrial-scale agricultural production, by explicitly referencing place or territory. This reconnects people, production and place in significant ways. Barham specifically investigates the French Appellation d'Origine Contrôlée (AOC) regime as a practical operationalisation of the terroir concept. Formal recognition as an AOC product requires satisfactory progress through several bureaucratic stages, each of which calls for moments of judgement. These decisions require choices to be made between natural factors, human factors or techniques and the history of the product, which combine to produce the 'typicity' of the product. While reinforcing Stanziani's insight about the negotiated nature of AOCs, Barham is more optimistic and views the drafting of an AOC specification as a combination of research-driven conclusions and negotiated outcomes. This permits market logic to co-exist with other values and ways of viewing the world. Also approaching terroir through the lens of social theory, Laurence Bérard - a respected ethnographer of GI products and communities - offers up a genealogy of this concept in Chapter 4. She describes its historical origins as a political resource, within the dual contexts of environmental determinism as well as the politics of retaining regional identities in the face of centralising pressures. Notably, she charts the rise of human or cultural factors and argues that this intergenerational, historical dimension to all such products, linked to collective memory, is what gives place depth. GIs therefore are both constituted by and help to make 'place'.

With a more nuanced understanding of the conceptual foundations in place, Part II proceeds to consider international GI protection. This sequence recommends itself because for many countries, GI protection obligations have been imposed by international treaties, as opposed to emerging first within domestic law. A pair of experienced commentators set out the present framework of international protection, commencing with Chapter 5 by Matthijs Geuze. He reviews WIPO's longstanding commitments in this area, outlining the contents of the three major agreements under its auspices - the Paris Convention of 1883, the Madrid Agreement for the Repression of False or Deceptive Indications of Source of 1891 and the Lisbon Agreement of 1958. These agreements continue to be influential because they have provided much of the raw material and shaped the 
parameters of the present international regime in TRIPS. Geuze is particularly well qualified to guide readers through the process culminating in the Geneva Act of 2015, which significantly revises the Lisbon Agreement. Key issues considered include the broadening of definitions, the basis for objecting to a registration, conflicts between trade marks and GIs, unprotected status for generic expressions and homonymous GIs (such as Pisco, claimed by both Peru and Chile). Daniel Gervais devotes Chapter 6 to the analysis of the GI provisions in TRIPS, noting that the resurgence of global interest in GIs is owed, in part, to the involvement of developing countries with large catalogues of regional speciality products. He retraces the origins of the GI provisions contained in Arts 22-24 of TRIPS while emphasising that these provisions directly allude to much unfinished business via a 'built-in agenda' for negotiations. A significant element of this is the commitment to establish an international register for wines and spirits. Gervais innovatively proposes that the (potentially upgraded) international register under the Lisbon Agreement may be a receptive home for giving effect to the wines and spirits register and to this extent, his chapter complements the analysis of the Lisbon regime in Geuze's.

The subsequent pair of chapters in Part II tackle the two most controversial aspects of the ongoing GI negotiations at the WTO. In Chapter 7 Michael Handler critically evaluates the case for extending the enhanced protection available to wines and spirits in Art 23 of TRIPS to all products. In what must surely be the definitive review of this topic, Handler convincingly argues that the EU - the principal proponent of extension - has failed to articulate a convincing argument for extension. While other justifications for extension might exist, the arguments presented by proponents are too simplistic. He concludes by labelling the Art 23 extension debate as something of a 'sideshow' when the real action seems to be taking place bilaterally, in the context of preferential trade agreements. The (re)turn to biliateralism is a significant development and is also noted by other contributors such as Taubman, Stern and myself. In Chapter 8, José Manuel Cortés Martín considers the options for establishing a multilateral register for wines and spirits, reviewing the three different visions of registration contained in EU-led, US-led and Hong Kong, China proposals. These have recently been amalgamated into a consolidated draft text, where two prominent and divisive issues are the legal effects of registration (is there a presumption of validity upon registration and should there be an obligation to consult the register?) and participation in the registration system (does it mandatorily cover the entire WTO membership or only those who opt in to this system?).

In the final contribution to Part II, Antony Taubman considers what it means for GI protection in TRIPS to itself be situated within the context 
of a broader multilateral trading system. This chapter identifies the central difficulty faced by proponents of international GI protection - the notion of territoriality usually limits the protection that is available within national jurisdictional boundaries, while meaning is fluid and varies with context. Since GI products are themselves traded across borders, the meaning of Champagne or Feta (origin-specific or generic?) will inevitably vary across markets. In these circumstances can negotiated outcomes creating specific lists of protected terms produce a trading system that is fairer and enhances overall public welfare? Taubman develops this line of analysis by identifying two methodologies or approaches to international trade negotiations. A 'fix-rules' approach - exemplified by TRIPS - settles on the objective rules expected to apply in the domestic regulatory contexts, so that national authorities interpret these internationally binding rules and apply them consistently. The second, a variant of the classic 'managed trade' or 'fix-outcomes' approach, would settle in advance what the outcomes should be. Bilateral agreements with annexes of protected terms or the Lisbon Register of protected appellations represent this approach, which determines in advance which designations would qualify as GIs and when they would cease to have generic significance. Therefore, what appears questionable to some IP practitioners and scholars - the artificial 'fixing' of semantic content - can be better explained when viewed from this multilateral trade perspective.

In Part III, the perspective shifts to national experiences and experiments with GI protection models. Stephen Stern draws on decades of experience as a GI litigator in Chapter 10, providing us with a detailed and engaging biography of Australian wine GI protection regimes across six distinct phases. Along the way there is coverage of the EU-Australia Wine Agreement (clearly qualifying as one of Taubman's 'fix-outcomes') as well as insights revealing the manner in which national regimes are influenced by international negotiations. Of particular interest is Stern's insider account of the geographical-boundary-delimiting difficulties over the course of the controversial Coonawarra wine region litigation. In Chapter 11, Delphine Marie-Vivien also draws on considerable reservoirs of fieldwork as well as academic experience when comparing the GI regimes of France, the EU and India. She asks whether handicrafts can be accommodated within a regime that has historically prioritised the link to origin emphasising natural (that is physical geography) features based on the archetypal subject matter categories of wines and agricultural products or foodstuffs. Marie-Vivien challenges the conventional distinction between agricultural products, wines and spirits on the one hand and crafts on the other, arguing that current registration practice and existing interpretations of the link requirement for agricultural products have already 
accommodated human or cultural factors to such an extent that excluding handicrafts is no longer justifiable. However, this should be counterbalanced by providing for two different levels of protection, depending on the strength of the link to the region of origin. Finally, Chapter 12 rounds off Part III with a fascinating and detailed account of the trio of concurrently applicable GI protection options in China. Drawing on her operational experience with GI registration, Haiyan Zheng considers the pros and cons of GI protection via trade mark law (as certification or collective marks), via a sui generis regime covering all products or via a sui generis regime specific to agricultural products. Each regime is administered by a different government agency or department, which gives rise to the potential for both systemic conflicts and overlaps. Different authorities may confer the same GI rights on different right holders, identify incompatible geographical boundaries for the same region and enforce different quality standards, so she favours the trade mark solution as the most effective one.

Part IV completes the volume with a survey of the most enduringly controversial or nascent issues presently confronting GI regimes. Burkhart Goebel (a rare breed of IP litigator with considerable GI experience) and Manuela Groeschl tackle the most controversial of these issues conflicts between trade marks and geographical indications - in Chapter 13. Drawing on both international law (primarily TRIPS) and European doctrinal materials, they plausibly suggest that disputes between these two categories of signs should be resolved in accordance with the well settled principles of priority, exclusivity and territoriality (or PET). Their preference is for the general trade mark approach to resolving conflicting rights in accordance with the 'first in time, first in right' principle (with room for exceptions), as opposed to sui generis approaches which would always prioritise GIs in such conflicts, because of their public values. In Chapter 14 Christopher Heath approaches the same disputed territory but adopts a distinctive method for doing so. In this exceptionally well researched contribution he compiles and analyses a vast swathe of litigated Budweiser disputes, between the Czech brewery Budvar and the American company Anheuser-Busch, spanning five continents and four decades. Heath fuses them into a lens to evaluate the effectiveness of international GI protection. He classifies them into cases involving a clash of trade marks, cases involving the Czech appellation 'Budejovicky Budvar/Budweiser Budvar' or its variants being protected under the Lisbon Agreement and cases involving appellation protection under bilateral agreements. Among the most original contributions of this chapter is the detailed analysis of divergent judicial interpretations of the Lisbon Agreement (Art 6 which prevents generic use is particularly controversial). His contribution acts not only as a counterfoil to some of the arguments in the previous chapter 
but also usefully supplements the analysis of the Lisbon Agreement undertaken in Part II.

The next two chapters approach the topic of GIs being facilitators of regional or territorial development at both theoretical and empirical levels. In Chapter 15 Dominique Barjolle draws on a combination of research expertise and consulting experience to analyse GIs within the context of markets while identifying the institutional factors contributing to successful GIs. Having identified the precise manner in which GIs add value (economic value by signalling product differentiation and guaranteeing quality), she emphasises the significance of well-designed organisations (the representative producer associations) as well as codes of practice in retaining that value. The chapter concludes by considering the extent to which local regions or territories can be the beneficiaries of this value creation and the potential impact of GIs on sustainable development. In both this chapter and the one that follows, the blend of theoretical framing and empirical detail greatly strengthens the arguments. Dwijen Rangnekar and Pranab Mukhopadhyay also consider the social gains and potential for regionally specific value creation in Chapter 16, through a detailed case study of the cashew-based spirit Feni from Goa. They explore the impacts that registration of Feni as a GI could have on stakeholders, concluding that legal protection is insufficient to sustain traditional smallscale producers, who are the principal intended beneficiaries. The central puzzle explored in this chapter is the apparent decline in both production and consumption of Feni within the state of Goa. Interestingly, changes in consumer tastes, linked to the entry of alternative spirit drinks into the Goan market could have eroded Feni's market share, which in turn suggests that enhanced legal protection in isolation will not be effective in reviving the fortunes of small-scale Feni producers.

The penultimate chapter considers the relatively recent argument that GI protection regimes can provide effective protection for indigenous or traditional knowledge. In Chapter 17, Brad Sherman and Leanne Wiseman approach this issue by teasing out the epistemic assumptions underpinning the link between product and place in international GI protection debates. Given the wine-specific origins of GI protection, they identify a scientifically verifiable causal connection between product and place (in the form of local environmental conditions affecting the ripening and flavour of grapes) as the archetype of the link requirement. However, this is increasingly problematic when it comes to artefacts with a greater human dimension, or when it comes to the needs of indigenous peoples with distinct epistemic frameworks and value systems. Sherman and Wiseman explore two approaches - one relating to defining unique or distinctive products by identifying parallels with the naming conven- 
tions used in identifying new botanical varieties; the other drawing upon the manner in which indigenous knowledge and links to place have been identified on their own terms (in accordance with the worldviews of indigenous communities) in the context of native title claims to land by Aboriginal communities in Australia. For instance links to place could be proved by allowing songs, dances, stories and paintings as valid categories of evidence. The chapter's value lies in the question it raises: viewed from the perspective of indigenous communities, is it realistic to expect that GIs can be used to protect Indigenous knowledge?

In the final chapter, I have (appropriately enough) considered the death of GIs, by analysing the legal test for genericide. Generic status is reached when a product no longer indicates geographical origin but merely indicates a class of products with certain qualities, such as cheddar cheese. While TRIPS provides that such terms are unprotected, the test for determining generic status is remarkably thin. This chapter draws comparatively on decisions across several jurisdictions to develop a detailed menu of options - both threshold issues and evidentiary categories - which need to be considered when applying the test for generic use in practice. The chapter emphasises that the overarching enquiry should be to assess consumer understanding of the disputed term, as opposed to strategic manoeuvres by producer interests on both sides of this debate.

Having hopefully whetted your appetite all that is left is to recommend this volume to you and to hope that you find it interesting. It has been both an education and a pleasure to gather together some of the most insightful and original research in this fascinating area. In an ideal world, without the constraints of space, the list of contributors would have been even longer. Other legal commentators whose research could have illuminated the pages of this volume include - in no particular order - Justin Hughes, Latha Nair, Michael Blakeney, Roland Knaak, Christine Haight Farley, Irene Calboli, Caroline le Goffic and Jacques Audier. Researchers from across the social sciences exploring the factual claims and policy underpinnings of GIs include Bertil Sylvander, Erik Thévenod-Mottet, Sarah Bowen, Philippe Marchenay, Giovanni Belletti, Cerkia Bramley and Kolleen Guy. My only consolation is that their works are referenced in the chapters which follow. What this volume does showcase is that a conversation has begun between the various research communities. It is one which will greatly enhance our understanding of Geographical Indications in the future. 
Dev S. Gangjee - 9781784719470 Downloaded from PubFactory at 04/26/2023 12:20:08AM via free access 